\title{
Notes on Operations Idaho Participation in NACO: The Effect on Idaho Corporate Name Authority Control
}

\author{
By Cheri A. Folkner and Barbara C. Glackin
}

In 2005 five Idaho institutions joined the Name Authority Cooperative Program (NACO) of the Program for Cooperative Cataloging in order to expand the underlying data that help library users find and identify resources and to improve cataloging efficiencies within the state. The objective of this study was to determine what effect this participation by Idaho institutions in the NACO program had on the authority control of Idaho agencies and other Idaho corporate entities. Data analysis of Idaho corporate name authority records showed this participation significantly increased authority control for these entities. In less than three years, Idaho institutions created more than 12 percent of the 1,763 Idaho corporate name authority records identified in the Library of Congress NACO Authority File.

uthority control in library catalogs has been described as "a traffic-direction $\mathbf{A}_{\text {system, gathering information under authorized headings and steering }}$ patrons away from dead-end searches." Name authority records in the library catalog contain information on people, companies, and places that tell the catalog user what form of a name is used in the catalog regardless of other names that the entity may use or have used in other contexts. This authorized name provides consistency for searching within the local library catalog or a larger shared catalog and enhances the ability of catalog users to find and identify resources in a library's collection. In an effort to help catalog users find and identity information on or by Idaho people, companies, or jurisdictions, several Idaho institutions joined the Name Authority Cooperative Program (NACO) of the Program for Cooperative Cataloging (PCC), an international cooperative cataloging effort to create and maintain the underlying data for name authority control. NACO (www.loc.gov/catdir/pcc/naco) allows individual institutions and groups of institutions, following a common set of standards and guidelines, to create and maintain (i.e., modify) authority records in the Library of Congress/NACO Authority File (LC/NAF). Institutions that complete basic NACO training and achieve independent NACO status are authorized to create and maintain name authority records in the LC/NAF for persons, corporate bodies (including jurisdictional areas), and uniform titles. Authorization to create and maintain series and music uniform title authority records requires additional training. The current study investigates what effect this participation by Idaho institutions in the NACO program had on the authority control of Idaho agencies and other Idaho corporate entities. An analysis of the 1,763 Idaho corporate name authority records identified in the LC/ NAF showed that Idaho institutions created 213 of those records.

The importance of authority record creation and maintenance has recently been reaffirmed in the final report of the Library of Congress Working Group

on the Future of Bibliographic Control. ${ }^{2}$ The Working Group was convened and

state.edu) is Catalog Librarian, and Barbara C. Glackin (barbaraglackin@ boisestate.edu) is Head of Cataloging and Online Catalog, Albertsons Library, Boise State University, Boise, Idaho.

Submitted September 8, 2008; tentatively accepted October 11, 2008, pending revision; revised and submitted November 25, 2008, and accepted for publication. 
charged by the Associate Librarian for Library Services at the Library of Congress (LC) to look at the future of bibliographic control in the twentyfirst century. In its report, issued in early 2008, the Working Group noted speculation from many members and clients of the library community that improvements in machine-searching capabilities would eliminate the need for authority control. The group concluded, "While such mechanisms as keyword searching provide extremely useful additions to the arsenal of searching capabilities available to users, they are not a satisfactory substitute for controlled vocabularies. Indeed, many machine-searching techniques rely on the existence of authoritative headings even if they do not explicitly display them."3 The Working Group recommended that the $\mathrm{LC}$ and the library community increase collaboration on authority record creation and maintenance as part of a strategy to continue to provide effective authority control and help manage the associated costs.

\section{Idaho's NACO Participation}

Prior to 2005, no Idaho institutions participated in the NACO program. Idaho State University was the first Idaho institution to participate when it joined the now defunct Utah-based Mountain West NACO Funnel Project in February 2005. Other Idaho institutions followed when the Idaho NACO Funnel Project was established in July 2005. A funnel project is "a group of libraries [that] join together to contribute name authority records to the master database" where "funnel members which create records in modest numbers are able to consolidate their efforts to make a larger contribution as a group." In fiscal year 2006, the PCC reported that nearly two-thirds of its members participated through funnel projects. ${ }^{5}$

Training for the Idaho NACO
Funnel Project was held July 11-15, 2005 , in Boise. The training was jointly funded by a Library Services and Technology Act grant administered by the Idaho State Library and matching funds provided by the libraries at Boise State University and the University of Idaho. Idaho NACO Funnel Project coordinator Linnea Marshall outlined the benefits of the NACO training:

Trainees who achieve the learning objectives of the NACO workshop will begin to create new and update existing authority records for Idaho names in the national name authority file. As these records become available, catalog librarians in Idaho (as well as in other states) will be able to refer to them when they are creating bibliographic records for their libraries' Idaho materials. This will save each cataloger time by not having to research a name or consult various rules to devise the correct form for a name. Cataloging will be more efficient and functional. Idaho catalog librarians will also benefit when they add bibliographic records to their catalogs created by other librarians who have access to accurate Idaho names through the name authority records created by Idaho libraries. As bibliographic records with uniform headings for Idaho agencies, organizations, and individuals are entered into the catalogs of Idaho libraries, reference librarians will find their work at helping patrons made easier by having consistent and reliable access to Idaho materials when the search term is a name. These benefits will extend to all Idaho libraries, not just those contributing to the Idaho NACO funnel project. $^{6}$

Twelve trainees from six institutions participated in the Idaho NACO training. Attendees included staff members from the institutions of the newly formed Idaho NACO Funnel Project: Boise Public Library, Boise State University, Idaho State Library (now the Idaho Commission for Libraries), University of Idaho, and Washington State's Highline Community College. Two participants from Idaho State University also attended the workshop. While Idaho State University was not a member of the Idaho NACO Funnel Project, attendance by its catalogers at the training workshop allowed staff from all Idaho NACO institutions to meet, interact, and discuss issues relevant to the state.

After the institutions from Idaho had been participating in NACO for more than two years, the authors investigated the level of that participation. Prior to training and approval as a funnel project, the institutions contributed no new records and modified no records; in the first full year following training (federal fiscal year 2006), the participating institutions contributed 349 new records and modified $88 .^{7}$ This moderated slightly in federal fiscal year 2007, when 253 new records were created and 70 were modified. ${ }^{8}$ Highline Community College has been an inactive member of the Idaho Funnel Project since September 2005, when it contributed two personal name authority records; it has not contributed any name authority records since that time.

\section{Literature Review}

The history, purpose, and benefits of authority control have been discussed extensively in the literature, including Auld's and Wolverton's general literature surveys and the published 
proceedings of a 2003 international conference in Florence, Italy, which covered theoretical and practical aspects of authority control..$^{9}$ Maxwell provided a detailed guide to authority work and how authority records are created. $^{10}$

The collaboration of cataloging agencies in creating and maintaining authority records has been well documented. In 2004, Wolverton conducted a survey to ascertain the authority control practices of 258 institutions designated by the year 2000 Carnegie Classification as Doctoral/Research Universities at either the Extensive or Intensive Level. ${ }^{11}$ Of the 192 universities that responded to the question "does your library create original authority records that are added to the national authority file?" 41 percent indicated they were contributing to the cooperative authority control effort. ${ }^{12}$ Riemer and Morgenroth, Buizza, and Byrum have reviewed the history of doing authority control cooperatively through NACO and other programs. ${ }^{13}$ Byrum outlined the reasons library administration should support participation in NACO, the benefits of NACO membership, and an overview of NACO funnel projects. Improving authority control for state-specific entities was the theme of a case study on the founding of the South Dakota NACO Funnel Project and its training component, which stated, "The state of South Dakota wished to form a funnel project in order to establish headings that were unique to South Dakota works, such as headings for South Dakota governmental entities, corporations, named places, and authors."14 This desire mirrors one of the primary reasons for the establishment of the Idaho NACO Funnel Project.

The literature on methods for evaluating the quality of authority records is less comprehensive. Burger included the most clearly defined evaluation areas for authority data: legality of data (i.e., conformity with cataloging codes and practices), legality of format (i.e., conformity with encoding standards), accuracy of data, accuracy of format, and comprehensiveness of data. $^{15}$ The quality standards used in the NACO program to evaluate authority records created and maintained by its members were discussed by Riemer and Morgenroth. ${ }^{16}$ The evaluation of corporate name authority records, a focus of this Idaho research, was investigated in an earlier study on whether the form of names constructed by catalogers reflected the name presented by the corporate entity on its website. ${ }^{17}$

\section{Idaho Study \\ Objectives}

The benefits of NACO to authority control via the LC/NAF are well established, and regional funnel projects play an important role, allowing the participation of institutions that, on their own, would not be able to meet the program's annual submission requirements. Idaho institutions joined as a NACO funnel project to help catalog users find and identify the many unique resources they hold and to improve cataloging efficiencies within the state. The objective of this study was to determine what effect Idaho NACO participation had on authority control for Idaho agencies and other Idaho corporate entities. Results were measured by

- the number of Idaho corporate name authority records created by Idaho institutions in the LC/ NAF; and

- the number of modifications made to existing Idaho corporate name authority records by Idaho institutions in the LC/ NAF.

The study was limited to corporate entities because of the relative ease in identifying those entities in the
LC/NAF. The authors could not determine a way to identify name authority records for persons related to Idaho.

The study had several secondary objectives. One was to test the assumption that, prior to Idaho institutions participating in NACO, the majority of Idaho corporate name authority records in the $\mathrm{LC} / \mathrm{NAF}$ were created by the LC and NACO institutions in states either adjacent to Idaho or in other parts of the western United States. While the authors assumed that institutions in states adjacent to Idaho would have the most Idaho-related material in their collections, the number of NACO institutions in those states is quite small. Therefore the authors further hypothesized that NACO institutions in nonadjacent western states may have created more Idaho corporate name authority records than NACO institutions in adjacent states. Another secondary objective was to examine the types of modifications made to Idaho corporate name authority records and to identify which institutions were modifying those records. Lastly, the study sought to identify and categorize major errors in Idaho corporate name authority records.

\section{Research Method}

To gather the data necessary for the study, two sets of Idaho corporate name authority records were retrieved from OCLC's authority files using the OCLC Connexion Cataloging Client:

- a set resulting from a search of the OCLC Authority File

- a set resulting from a series of searches of OCLC's LC Authority History File

Each OCLC authority file contains both the name authority records and subject authority records distributed by the LC. Only the current version of an authority record is contained in the OCLC Authority File. From this authority file, current versions 
of Idaho corporate name authority records were retrieved and analyzed. Using the creation date retained in each record, these records provided an overview of existing Idaho corporate name authority records from the earliest creation date in the record set (May 9, 1977) through December 31, 2007.

OCLC's LC Authority History File contains all versions of an authority record. ${ }^{18}$ It tracks the evolution of each authority record, including superseded versions and versions sent from OCLC to the LC and then distributed back to OCLC. It also includes records deleted from the authority file. The record set drawn from this authority file provided data for determining the number and types of modifications made to existing Idaho corporate name authority records.

The authors developed search strategies to retrieve the Idaho corporate name authority record sets that worked within the interactive searching capabilities of OCLC's Connexion Client and overcame the limitations of the data encoded in the records. They also accounted for the fact that OCLC's authority files include name authority records and subject authority records in a single file. To determine the number of Idaho corporate name authority records, retrieving as many relevant authority records as possible was important. Consequently, the authors structured the searches to maximize recall rather than precision. The number of irrelevant authority records retrieved was less important because those records were identified post-search and removed from the record sets. Relevant records were defined as Idaho corporate name authority records created before January 1, 2008. For this study, the working definition of an Idaho corporate name authority record was an authority record following descriptive rather than subject cataloging conventions for a corporate body located in Idaho. The Anglo-American
Cataloguing Rules, 2nd ed., rev., which is NACO's descriptive cataloging standard, defines a corporate body as an "organization or group of persons that is identified by a particular name and that acts, or may act, as an entity. Typical examples of corporate bodies are associations, institutions, business firms, nonprofit enterprises, governments, government agencies, religious bodies, local churches, and conferences." ${ }^{.19}$ Although the definition is relatively clear, in some cases determining when an authority record for an entity should be created using descriptive cataloging conventions can be ambiguous. NACO uses the LC's Subject Cataloging Manual for guidance on whether to use descriptive cataloging conventions or subject cataloging conventions when creating an authority record. ${ }^{20}$

This study used the prefixes in valid LC control numbers (LCCNs) in the authority records to quickly ascertain which cataloging conventions were used. The authors retained authority records with LCCN prefixes beginning with the letter $n$, which indicates they were created using descriptive cataloging conventions, in the records sets; authory records with LCCN prefixes starting with an $s$, which indicates they were created using subject cataloging conventions, were removed. ${ }^{21}$ Other types of name authority records removed were those for persons, series, uniform titles, and name-titles. The authors extracted as much information as possible from the authority records to minimize manual review and data entry. Throughout this paper, the parts of the record from which data were pulled will be discussed and reported in terms of "MARC 21 Format for Authority Data." 22

\section{Overview Record Set from the OCLC Authority File}

Records from the OCLC Authority File provided an overview of existing Idaho corporate name authority records created before January 1, 2008. On May 1, 2008, the authors retrieved a set of 2,432 name authority records by searching the corporate/conference name index for the words "Idaho" or "Boise." These two search terms were used because they are mostly unique to Idaho and most corporate entities would be state agencies, related to a state institution of higher learning, or related to Boise, the major population center of Idaho. A total of 669 records were deemed irrelevant and removed. More than 85 percent of the records deemed irrelevant were created using subject cataloging conventions or were series authority records. The other irrelevant records were created in 2008, determined not to be entities located in Idaho, name-title authority records, or personal name authority records. The authors named the remaining set of 1,763 relevant records the "overview record set."

The effectiveness of this method-retrieving a broad set of authority records and removing irrelevant ones-was measured by determining how many records from a set of known relevant authority records were captured and retained. Determining method effectiveness was particularly important because the authors limited the search to the terms "Idaho" or "Boise" and did not include other Idaho municipality or county names. From July 18, 2005, through December 31, 2007, Idaho NACO Funnel Project participants created 161 Idaho corporate name authority records and modified 39 Idaho corporate name authority records as tracked by the Idaho NACO Funnel Project coordinator. ${ }^{23}$ Of the 200 records created or modified by the Idaho NACO Funnel Project participants, the authors captured 180 and retained them in the overview record set. Those not captured were for entities whose names did not include either "Idaho" or "Boise," and descriptive cataloging conventions did not require the addition of a place qualifier to the 
authorized name. Although ideally all of the relevant records would have been retrieved and retained, the 90 percent recall rate gave the authors confidence that the method was effective enough to make conclusions from the data.

The authors analyzed data in the overview record set to identify the institutions that created the records, the records' creation dates, and the institutions that had modified the records. The following information was used in this analysis:

- original cataloging agency from the cataloging source field (subfield code "a" in field 040)

- date created from the "date entered on file" character positions in the fixed-length data elements field (character positions 00-05 in field 008)

- modifying agency or agencies from the cataloging source field (subfield code "d" in field 040)

- source citation from the "source data found" field (subfield code "a" in field 670)

The institutions that created or modified the authority records were divided into the following categories: Idaho institutions (the four active Idaho NACO Funnel Project member institutions plus Idaho State University), regional institutions (ten institutions in states adjacent to Idaho), western institutions (nine institutions in states not adjacent to Idaho, but considered part of the western United States), LC (two divisions); and other institutions (forty institutions not part of the other categories).

\section{3-7 Record Set from OCLC's LC Authority History File}

The second set of records used in this study, called the "2003-7 record set," was based on records retrieved from a series of searches in OCLC's LC Authority History File. This set provided data for determining the number and types of modifications made to existing Idaho corporate name authority records. The authors conducted five searches, one for each year from 2003 through 2007, to cover the $2^{1 / 2}$ years prior to the Idaho NACO Funnel Project training and establishment and the $2^{1 / 2}$ years following. Of the four search indexes available in OCLC's LC Authority History File, two were used to construct the search queries: the heading word index, which indexes all 1xx fields and 4xx fields in an authority record except the 148 and 448 chronological terms fields, and the LCCN word index, which indexes the 010 field..$^{24}$ The constant elements in each search were the words "Idaho" or "Boise" in the file's heading word search index. The authors used the year element in the LCCN word search index to limit records to the five years of interest because OCLC's LC Authority History File has no date index. The year element corresponds to the year in which the LCCN was assigned. The system automatically assigns the LCCN to each newly created record at the time the record is added to the OCLC Authority File. In rare cases, however, the year element in the LCCN does not correspond to the year a record was created. When a record is created in a local file in one year and then added to the OCLC Authority File in another, the year of creation in the fixed-length data elements field will differ from the year element in the LCCN. This did not affect the study because, until the record is actually added to the OCLC Authority File and distributed to the $\mathrm{LC} / \mathrm{NAF}$, it is not available for authority control beyond that local file. "MARC 21 Format for Authority Data" notes another case where the year element in the LCCN does not correspond to the year the record was created: "In name authority records that were converted retrospectively by an agency under contract to LC, the digits 50 were used for the year for name authority records." ${ }^{25}$ That retrospective conversion took place in 1979, which is prior to the years of interest for this record set. ${ }^{26}$

The authors searched OCLC's LC Authority History File, incorporating both the constant search elements and a LCCN year search element for each year of interest. For example, to retrieve the Idaho corporate name authority records for 2003, the following search string was used:

me: idaho or me: boise and lccn: 2003-*

The OCLC system converted that string to:

$$
\begin{aligned}
& \text { ((me:\{“idaho”\}) or me:\{“boise”\}) } \\
& \text { and lccn:\{“2003-"*”\} }
\end{aligned}
$$

The authors manually removed irrelevant records from the 892 authority records retrieved. A total of 612 authority records remained in the 2003-7 record set. As in the case of the overview record set, the effectiveness of this method to retrieve relevant authority records was measured. Of the 161 Idaho corporate name authority records created by Idaho NACO Funnel Project participants from 2005 through 2007, 141 records, or 88 percent, were captured and retained. Again, the effectiveness of the method was deemed sufficient to draw conclusions using the data obtained.

During the manual review, the authors tracked the history of each relevant authority record in this record set and recorded the following data: type of government agency, the number of modifying agency subfields, "modification instance" characterization, and existing errors in the current version of the authority record. A "modification instance" was defined as an instance when a change occurred between versions of an authority record, excluding changes in either the date of the last 
replace field or the authority history timestamp. These excluded changes were not considered modifications to the records because they occurred automatically during the authority record distribution cycle to and from the LC. The authors recorded several characteristics for each modification instance:

- the modifying agency

- the type of modification

- whether there were multiple major modifications made during the modification instance

- the date of the modification instance

Initially, the intent was to count the number of modifying agency subfields to determine the number of modification instances for each authority record. But, like bibliographic records in OCLC, modification transactions are not always reflected with an addition of a modifying agency subfield. Hence, no one-to-one correspondence exists between the number of modifying agency subfields and the number of modification instances. Of the 198 name authority records that had modification instances, 81 had more modification instances than the number of modifying agency subfields reflected in the 040 field. For the majority of those (96 percent), there was a difference of 1 between the number of modification instances and the number of modifying agency subfields. While the number of modifying agency subfields gives an indication of modification frequency, it does not provide complete information.

Recording modification instance characterization required additional operating assumptions and definitions. As noted, a modifying agency subfield is not always added to the 040 field when a record is modified. If a modification instance occurred and no modifying agency subfield was added to the 040 field, the authors made the following assumptions:
- If a system control number (field 035) was added or removed, OCLC was assumed to be the modifying agency.

- If a record was deleted because it was wrongly in the LC/NAF, it was a duplicate of another authority record, or for an indeterminable reason, the $\mathrm{LC}$ was assumed to be the modifying agency.

- For all other cases, the preceding modifying agency was assumed to be the subsequent modifying agency.

Although multiple modifications may have been made in each modification instance, the authors used a controlled vocabulary to determine and record the most significant modification in a modification instance. As part of the controlled vocabulary development, each modification was ranked in order of significance and categorized as either a major or minor modification. Modifications that affected either an access point (the authorized form of the name or its cross-references) or the retrieval of the authority record during a search of the authority file were defined as major modifications. This definition is similar to that of errors in "critical areas" within an authority record used by past NACO quality review processes. ${ }^{27}$ Riemer and Morgenroth reported those critical areas to be "headings, references, and MARC tagging" and noted that errors "would no longer be tallied for incorrect diacritics or capitalization. ${ }^{\prime 28}$ The difference in the study reported here is that the authors categorized modifications in the capitalization or diacritics of an access point as major modifications. The controlled vocabulary used and the major or minor category of each is shown in the appendix.

The authors assumed some modifications to be algorithmic modifications performed by the system at OCLC. These included the addition and removal of system control numbers and the addition of both a geographic area code (043 field) and a geographic subdivision linking field (781 field). These algorithm modifications were excluded from the data analysis because they were not the result of direct action by a NACO institution.

Errors in the current version of an authority record were recorded following a similar method to that used for recording type of modification. The controlled vocabulary for error recording was based on the vocabulary used for recording type of modification.

\section{Findings and Discussion}

The major focus of this study was to determine what effect the participation of Idaho institutions in the NACO program had on the authority control of Idaho corporate names. Specifically, did the number of Idaho corporate name authority records in the LC/NAF significantly increase after the Idaho NACO institutions began contributing authority records in late July 2005? Figure 1 shows that Idaho institutions have significantly increased the number of Idaho corporate name authority records. Data from the overview record set show that during the time Idaho institutions have been contributing authority records, they created an average of 85 Idaho corporate name authority records per year while, all other institutions combined created an average of fifty Idaho corporate name authority records per year. Together, Idaho institutions are creating Idaho corporate name authority records at a 70 percent greater rate than that of other institutions combined.

This simple average does not take into account whether there are trends over time. If trends exist and they are taken into account, is the effect of Idaho institutions on the authority control of Idaho corporate names still 


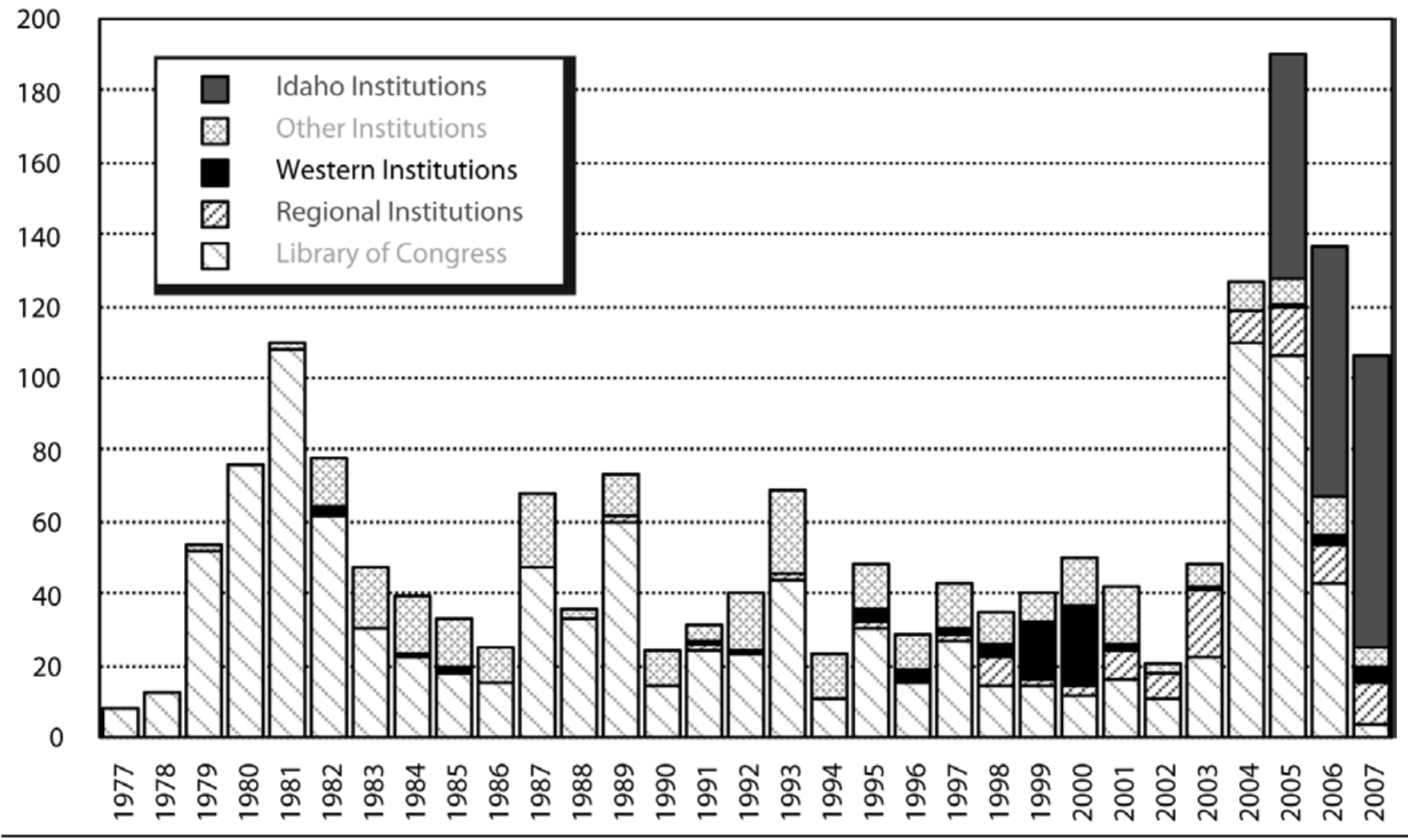

Figure 1. Number of Idaho Corporate Name Authority Records Created by Year and by Institution Category

significant? An analysis of the data over time supports the conclusion that it is. While figure 1 does show a dramatic jump in the number of Idaho corporate name authority records created, the jump occurred in 2004, which is before the Idaho institutions began participating in NACO. The LC created 110 and 106 Idaho corporate name authority records in 2004 and 2005 respectively. A further investigation of these 216 name authority records showed that 186 of the records, 93 in each 2004 and 2005, were created by the National Union Catalog of Manuscript Collections for oral histories at the Idaho State Historical Society. The specific number of Idaho State Historical Society oral histories cataloged by the National Union Catalog of Manuscript Collections during 2004 and 2005 could not be readily determined; information was not available on whether that rate of cataloging for Idaho State Historical Society materials would be sustained. To compensate for the possibility that this rate would continue, the authors calculated a two-year moving average for the number of Idaho corporate name authority records created, excluding those contributed by Idaho institutions. This moving average can be used to predict the number of Idaho corporate name authority records that would have been created without the participation of Idaho institutions. Figure 2 shows that without the contributions of Idaho institutions, the predicted number of Idaho corporate name authority records would have been much lower than the actual number created in 2005, 2006, and 2007, a difference of 63, 40, and 60 respectively. Regardless of whether a simple yearly average or a two-year moving average is used to analyze the number of Idaho corporate name authority records created, the effect of Idaho institutions on those numbers is significant.

Participation of Idaho institutions in the NACO program has significantly increased the number of Idaho corporate name authority records created, but has that participation similarly affected the maintenance of Idaho corporate name authority records? As Auld noted, authority control "is based on the maintenance of a file in which headings, variant forms of headings, sources, and other related data are recorded." ${ }^{29}$ So, to the extent that effective authority control depends on the creation of authority records, it also depends on the maintenance or modification of those records to reflect the earlier, later, and variant names of an entity. As an indicator of the level of maintenance activity for Idaho corporate name authority records, did the number of modification instances increase during the time that Idaho institutions have participated in NACO? The answer is a qualified no, but not definitively so because of the limitations of the longitudinal data available in this study.

The 2003-7 record set data analysis 


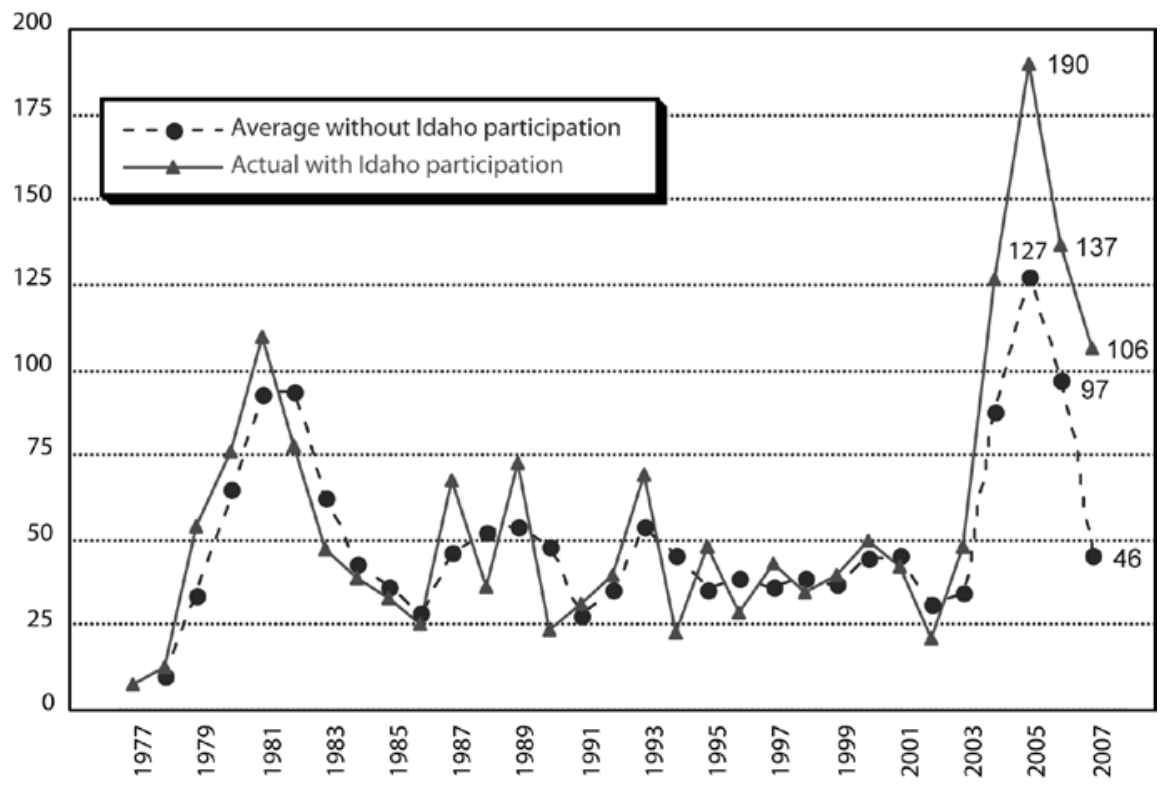

Figure 2. Thirty Year Trend Data for Average and Actual Idaho Corporate Name Authority Records Created

showed that the number of modification instances per month, excluding modification instances performed algorithmically by OCLC, averaged 1.7 from January 2003 through July 2005 while the average for the period of August 2005 through December 2007 was 1.3. A two-sample unequal variance t-test shows that there is no statistical difference between the averages $(t(52)$ $=0.90, p<0.01)$, and this seems to indicate that the number of modification instances has stayed constant since Idaho institutions have participated in NACO. However, modification of a name authority record generally occurs when a name changes or variants of the name are used; these instances occur over time. The 2003-7 record set was limited to Idaho corporate name authority records created from 2003 through 2007, and this five-year snapshot may not have been long enough for those name changes and variants to occur, be discovered during the cataloging process, and then be reflected in the name authority records.

\section{Secondary Results}

The authors went into the study with the assumption that the LC or regional institutions created the majority of the Idaho corporate name authority records in the LC/NAF. Figure 3 shows that this assumption is correct; the LC created 61 percent of the Idaho corporate name authority records, and regional institutions created 6 percent. The fact that western institutions accounted for the creation of only 4 percent of the Idaho corporate name authority records was unexpected. Institutions (other than the LC) outside of the western United States created 17 percent of the records. Institutions in twenty-nine states have created at least one Idaho corporate name authority record. That Idaho-related materials are being cataloged for collections located across such a broad geographic area was also unexpected. The major effect Idaho institutions have had on the creation of Idaho corporate name authority records is reflected in figure 3. It shows that Idaho institutions created 12 percent of the total number of Idaho corporate name authority records from 1977 to 2007 . Idaho institutions participated in NACO for only 8 percent of that time.

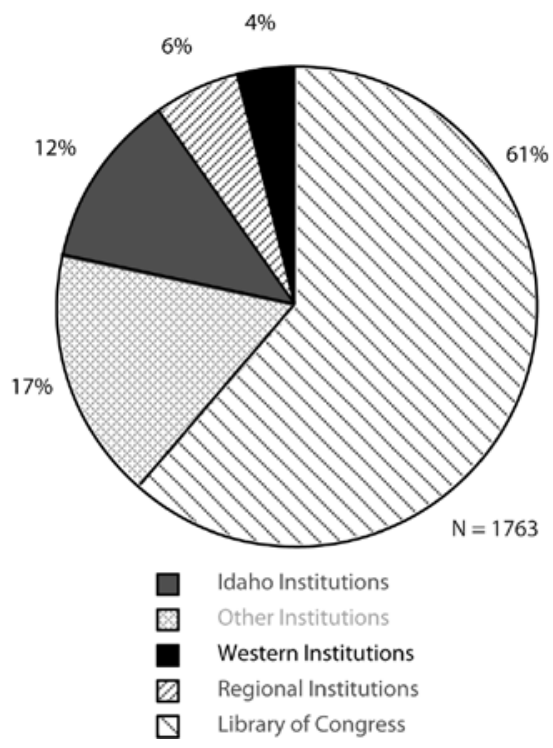

Figure 3. Distribution of the Creation of Idaho Corporate Name Authority Records by Institution Category

To determine what modifications were made most frequently, the authors analyzed the types of modifications made to Idaho corporate name authority records in the 2003-7 record set. They found 235 modification instances in the 612 records examined. Direct action by a NACO institution, not an algorithmic action, accounted for 92 modification instances. Of those, 64 percent were determined to be major modifications. Table 1 shows the breakdown of modifications by major or minor category and the type of modification. Modification of the form of an access point accounted for 24 of the modifications, and 24 modifications were made to the crossreference structure of the records. If the authors had used the critical error criteria reported by Riemer and Morgenroth, they would have categorized 4 modifications as minor, and they would have reduced major modifications from 64 to 60 percent of the modification instances.

Of the 612 records in the 2003-7 record set, only 5 records, or 0.8 percent, contained a major error in the current version. Those errors were of the following types: 
- the form in the 1xx field was wrong

- the form in the $4 x x$ field was wrong

- a duplicate name authority record already existed

- the fixed field code for reference status was wrong

- the fixed field code for subject use was wrong

While 0.8 percent is a low percentage of major errors, these errors do affect the ability of catalog users to find and identify information. The errors have since been corrected in the LC/NAF.

\section{Conclusion}

Through the participation of Idaho institutions in the NACO program, authority control of Idaho agencies and other Idaho corporate entities has significantly increased when measured by the number of name authority records created for Idaho corporate bodies. From July 2005 through December 2007, Idaho institutions created more than 12 percent of the Idaho corporate name authority records identified in the LC/NAF, which includes Idaho corporate name authority records created as far back as 1977. The effect Idaho institutions have had on the maintenance of Idaho corporate name authority records is more nebulous because of limitations of the longitudinal data available. Further investigation is required to determine what effect Idaho NACO institutions have had on that maintenance over a longer, more representative period of time.

This study was undertaken to determine whether the Idaho NACO funnel project was meeting its objetive to create new and update existing authority records for Idaho names. Additional research is needed to determine if other NACO libraries or funnel projects established for the purpose of creating and maintaining authority records associated with their surrounding geographic areas have a comparable effect.

\section{References and Note}

1. Kathleen L. Wells, "Authority Control in Mississippi Public and Academic Libraries: A Survey," Technical Services Quarterly 18, no. 2 (2000): 2.

2. Library of Congress Working Group on the Future of Bibliographic Control, On the Record (Washington, D.C.: Library of Congress, 2008), www.loc.gov/bibliographic-future/ news/lcwg-ontherecord-jan08-final .pdf (accessed Mar. 20, 2009).

3. Ibid., 19.

4. John D. Byrum, "NACO: A Cooperative Model for Building and Maintaining a Shared Name Authority Database," Cataloging \& Classification Quarterly 38, no. 3/4 (2004): 244.

5. Program for Cooperative Cataloging, Annual Report FY06 (Washington, D.C.: Library of Congress, 2006): 5, www.loc.gov/catdir/pce/ PCCAnnualFY06.pdf (accessed Apr. 20, 2009).

6. Linnea Marshall, grant application for grant agreement no. T05220-05, Idaho State Library, Library Services and Technology Act, 2005, 3-4.

7. LC Acquisitions and Bibliographic Access Directorate, "Program for Cooperative Cataloging StatisticsNACO/BIBCO/CONSER/SACO, Annual Compilation FY2006," www loc.gov/catdir/pcc/stats (accessed Mar. 20, 2003).

8. LC Acquisitions and Bibliographic Access Directorate, "Program for Cooperative Cataloging StatisticsNACO/BIBCO/CONSER/SACO, Annual Compilation FY2007," www loc.gov/catdir/pcc/stats (accessed Mar. 2, 2009).

9. Larry Auld, "Authority Control: An Eighty-Year Review," Library Resources \& Technical Services 26, no. 4 (1982): 319-30; Robert E. Wolverton, "Becoming an Authority on Authority Control: An Annotated Bibliography of Resources," Library Resources \& Technical Services 50, no. 1 (2006): 31-41; "Authority Control: Definition and International
Table 1. Types of Modifications Made to Idaho Corporate Name Headings Created 2003-7

\begin{tabular}{|c|c|}
\hline Type of Modification & Instances \\
\hline \multicolumn{2}{|l|}{ Major } \\
\hline 1xx form changed[a] & 15 \\
\hline $4 \mathrm{xx}$ added $[\mathrm{b}]$ & 13 \\
\hline 4xx form changed[a] & 8 \\
\hline earlier/later 5xx added[b] & 7 \\
\hline record deleted - duplicate & 3 \\
\hline $010 \$ \mathrm{z}$ added & 3 \\
\hline record deleted - SH & 3 \\
\hline subject use changed & 1 \\
\hline 5xx form changed[a] & 1 \\
\hline $\begin{array}{l}\text { earlier/later } \$ \mathrm{w} \\
\text { removed[b] }\end{array}$ & 1 \\
\hline 4xx changed to $5 \mathrm{xx}[\mathrm{b}]$ & 1 \\
\hline $5 \mathrm{xx}$ added $[\mathrm{b}]$ & 1 \\
\hline $\begin{array}{l}\text { record deleted - unknown } \\
\text { reason }\end{array}$ & 1 \\
\hline $4 \mathrm{xx}$ removed[b] & 1 \\
\hline Total & 59 \\
\hline \multicolumn{2}{|l|}{ Minor } \\
\hline 670 modified & 13 \\
\hline none determined & 6 \\
\hline 670 added & 4 \\
\hline 781/043 added & 3 \\
\hline 675 added & 2 \\
\hline source fixed field changed & 1 \\
\hline 675 modified & 1 \\
\hline 781 added & 1 \\
\hline $010 \$ \mathrm{z}$ removed & 1 \\
\hline 667 removed & 1 \\
\hline Total & 33 \\
\hline Grand Total & 92 \\
\hline
\end{tabular}

[a] access point form modification

[b] cross reference structure modification

Experience, Part 1,” ed. Arlene G. Taylor and Barbara B. Tillet, special issue, Cataloging \& Classification Quarterly 38, no. 3/4 (2004). This special edition contains papers presented at the International Conference on Authority Control: Definition and International Experiences held at the Convitto della Calza, Florence, Italy, 
Feb. 10-12, 2003.

10. Robert L. Maxwell, Maxwell's Guide to Authority Work (Chicago: ALA, 2002).

11. Robert E. Wolverton, "Authority Control in Academic Libraries in the United States: A Survey," Cataloging \& Classification Quarterly 41, no. 1 (2005): 111-31.

12. Ibid., 119 .

13. John J. Riemer and Karen Morgenroth, "Hang Together or Hang Separately: The Cooperative Authority Work Component of NACO," Cataloging \& Classification Quarterly 17, no. 3/4 (1993): 127-61; Pino Buizza, "Bibliographic Control and Authority Control from Paris Principles to the Present," Cataloging \& Classification Quarterly 38, no. 3/4 (2004): 117-33; Byrum, "NACO."

14. Dustin P. Larmore, "A New Kid on the Block: The Start of a NACO Funnel Project and What is Needed to Start Your Own," Cataloging \& Classification Quarterly 42, no. 2 (2006): 76.

15. Robert H. Burger, Authority Work: The Creation, Use, Maintenance, and Evaluation of Authority Records and Files (Littleton, Colo.: Libraries
Unlimited, 1985).

16. Riemer and Morgenroth, "Hang Together or Hang Separately."

17. Qiang Jin, "Is the Current Way of Constructing Corporate Authority Records Still Useful?” Information Technology \& Libraries 24, no. 2 (2005): 68-76.

18. OCLC, Authorities: Search Authority Files (Dublin, Ohio: OCLC, 2008), www.oclc.org/support/documentation/ connexion/client/authorities/search auth/searchauthorityfile.pdf (accessed Mar. 20, 2009).

19. Anglo-American Cataloguing Rules, 2nd ed., 2002 rev., 2005 update (Ottawa: Canadian Library Assn.; London: Library Assn. Publishing; Chicago: ALA, 2005): appendix D-2.

20. Library of Congress, Cataloging Policy and Support Office, Subject Cataloging Manual: Subject Headings, 5th ed., 2008 update (Washington, D.C.: Library of Congress, 2008): H 405.

21. Library of Congress Network Development and MARC Standards Office, "MARC 21 Format for Authority Data, 010-Library of Congress Control Number" (Washington, D.C.: Library of
Congress, 2007), www.loc.gov/marc/ authority/ad010.html (accessed Mar. 20, 2009).

22. Library of Congress Network Development and MARC Standards Office, "MARC 21 Format for Authority Data," 1999 ed., update no. 1 (Oct. 2001) through no. 8 (Oct. 2007), www.loc.gov/marc/authority/ ecadhome.html (accessed Mar. 20, 2009).

23. Linnea Marshall, "ID NACO funnel stats," e-mail message to authors with attachment, "New headings created through Idaho funnel.xls," May 5, 2008.

24. OCLC, Authorities: Search Authority Files (Dublin, Ohio: OCLC, 2008).

25. Library of Congress Network Development and MARC Standards Office, "MARC 21 Format for Authority Data, 010-Library of Congress Control Number."

26. Judith A. Kuhagen, "Standards for Name and Series Authority Records," Cataloging \& Classification Quarterly 21, no. 3/4 (1996): 131-54.

27. Riemer and Morgenroth, "Hang Together or Hang Separately," 141.

28. Ibid

29. Auld, "Authority Control," 319.

\section{Appendix. Controlled Vocabulary Used and Major and Minor Category of Each}

$\begin{array}{ll}\begin{array}{l}\text { Significance } \\ \text { Rank }\end{array} & \text { Vocabulary } \\ 1 & \text { record deleted - duplicate } \\ 2 & \text { record deleted - SH } \\ 3 & \text { record deleted - unknown reason } \\ 4 & 1 \times x \text { form changed } \\ 5 & \text { earlier/later 5xx added } \\ 6 & \text { earlier/later 5xx removed } \\ 7 & 4 x x \text { changed to } 5 x x \\ 8 & 5 x x \text { added } \\ 9 & 5 x x \text { removed } \\ 10 & 5 x x \text { form changed } \\ 11 & 5 x x \text { changed to } 4 x x \\ 12 & 4 x x \text { added } \\ 13 & 4 x x \text { removed } \\ 14 & 4 x x \text { form changed }\end{array}$

\section{Definition}

record was deleted because there was a duplicate NAR

record was deleted and replaced by a subject authority record

record was deleted for an indeterminable reason

form of 1xx changed and/or 1xx tag type changed (includes data entry corrections)

addition of 5xx including a $\$ \mathrm{w}$ for an earlier or later heading

removal of 5xx including $\$ \mathrm{w}$ for an earlier or later heading

$4 \mathrm{xx}$ changed to $5 \mathrm{xx}$

addition of 5xx that does not include a $\$ \mathrm{w}$ for an earlier or later heading

removal of $5 \mathrm{xx}$ that does not include a $\$ \mathrm{w}$ for an earlier or later heading

form of $5 \mathrm{xx}$ changed and/or 5xx tag type changed (includes data entry corrections)

$5 \mathrm{xx}$ changed to $4 \mathrm{xx}$

addition of $4 \mathrm{xx}$

removal of $4 \mathrm{xx}$

form of $4 \mathrm{xx}$ changed and/or 4xx tag type changed (includes data entry corrections)

Category
major
major
major
major
major
major
major
major
major
major
major
major
major
major


earlier/later \$w added

earlier/later $\$ \mathrm{w}$ removed

earlier/later \$w changed

subject use changed

$010 \$ \mathrm{z}$ added

$010 \$ \mathrm{z}$ removed

670 added

670 removed

670 modified

675 added

675 removed

675 modified

667 added

667 removed

667 modified

source fixed field changed
$\$ \mathrm{w}$ for earlier or later heading is added to an existing 5xx

major

$\$ \mathrm{w}$ for earlier or later heading is removed from an existing $5 \mathrm{xx}$

major

$\$ \mathrm{w}$ for earlier or later heading is changed but not removed from an existing 5xx

major fixed field for subject use changed

major

addition of $\$ \mathrm{z}$ for the deleted record to the "kept" record

major

removal of $\$ \mathrm{z}$ for any reason

minor

670 added

minor

670 removed

minor

670 modified

minor

675 added

minor

675 removed

minor

675 modified

minor

667 added

minor

667 removed

minor

667 modified

minor

source fixed field changed 